\title{
Quine's Naturalized Epistemology and the Issue of Knowledge Productivity
}

\author{
Dr. Omotosho I.F. \\ Lecturer, Federal Polytechnic Ede, Osun State
}

\begin{abstract}
Since Locke, empiricism has sought to deduce the knowledge of the world in one way or the other from sense experience. The aim of this episiemology has been twofold; to justify and deduce the truth of nature from sensory evidence and to define those truths in terms of observation and logico mathematical auxiliaries. The chief aim of which is to attain absolute certainly in our knowledge of the world. However, Ouine observes that this attempt of normative or traditional epistemology to provide a foundation of science has failed because all efforts of the empiricist philosophers have not been productive. Quine concludes on this basis that traditional epistemology can never produce knowledge or criterion of knowing. He therefore calls for the abandonment of traditional epistemology on the basis that it cannot produce knowledge. This paper examines his arguments for the claim that traditional epistemology is unproductive and can never produce knowledge. The paper reveals that the call is untenable as his leap from "It has not" to ' 'it cannot" is unjustifiable. The paper reveals further that it is the aim of traditional epistemology to justify science from sense experience and so far it is in the business of doing this, one can say it is productive.
\end{abstract}

DOI: $10.7176 / \mathrm{JPCR} / 40-03$

\section{INTRODUCTION}

Epistemology before Quine has been looking for foundation on which to build the edifice of knowledge. This desire to attain absolute certainty in our knowledge of the world was something empiricism had inherited from the seventeenth century rationalist philosopher. Rene Descartes (Quine; 1985,1, 2).

Empiricist philosophers after Descartes have also sought a first philosophy or metaphysics. That is, a theory of knowledge that will establish the rationale for indubitable or infallible propositions of sense and prescribe conditions for deducing propositions of science from indubitable propositions of sense. These goals of epistemology - radical empiricism as Quine calls them. (Quine 1985; 1) have not been possible despite the effort of philosophers since John Locke (John Locke's essay) and till recently before Quine (Rudolf catnap's auflau) (Quine; 1985; 1). Since this attempt has not yielded result,. Quine argues that traditional epistemology should be abandoned. Quine's reason is that it is unproductive that is, it has not produced knowledge and therefore cannot produce a viable theory of knowledge.

This paper examines Quine;s claim that traditional epistemology is unproductive (knowledge productivity is nil) because it is not the goal of epistemology to justify science on the basis of observation. The paper reveals that it is the aim of traditional epistemology to justify and produce criterion of knowledge as well as showing whether a belief is justified or not. The paper also reveals that Quine's leap from "it has not" to "it cannot" is unjustifiable. So, his call for the abandonment of traditional epistemology is untenable.

\section{METHODOLOGY}

This research employed the philosophical methods of analysis, argumentation and criticism to study data collected. The sources of data collected included books, journals and the internet.

\section{Quine's argument for the rejection of traditional epistemology}

The first step Quine takes in his essay "epistemology naturalized" (Quine 1985) is to reject first philosophy - the aims or tasks of traditional epistemology. Traditional epistemology is involved in two fold task. The first is in providing or identifying the regulating criterion of knowledge or conditions (criteria) of knowledge. The second task is that of determining, based on this criterion (criteria), whether or not we truly have knowledge or whether or not a claim is justified (known) or not. This twofold task is referred to as first philosophy because it is analytically prior to all our empirical knowledge. In short, traditional epistemology is concerned with the search for the foundation and justification of scientific knowledge,

However, Quine rejects this concern as the task of epistemology (Quine 1985; 18, 19). He also argues that traditional epistemology's attempt to find foundation and justification for scientific knowledge outside of science or prior to science has been unproductive or unfruitful or moribound (Quine ,1985; 19, 20). All the attempt of previous philosophers before him has not only failed to produce the criteria for knowing but has not been able to point to a claim that can be said to be justified or known.

At this juncture, it should be noted that traditional epistemology is reacting to the skeptical challenge that knowledge is impossible(Oke;1990,9,10), For traditional epistemology, knowledge of the external world is 
possible. The skeptics had claimed that knowledge is certainty.and that knowledge is not possible $(\mathrm{Oke} ; 1990,9)$. Traditional epistemology agrees with the skeptics that knowledge is certainty but rejects the skeptic's conclusion that knowledge is impossible, hence the search for certainty (knowledge) In his article, "epistemology naturalized" (Quine, 1985,1-25 ) Quine, argues that epistemology is concerned with the foundation of science which includes the study of the foundation of mathematics (Quine,1985: 15). He then notes a parallel between mathematics and epistemology. According to him both mathematics and epistemology pursue both "conceptual" and "doctrinal" projects.

The conceptual project is concerned with meaning while the doctrinal project is concerned with truth. Conceptually, epistemologists had hoped to clarify the meaning of the terms of .scientific knowledge in sensory terms just as mathematicians had sought to define mathematical terms in logical and set theoretical terms. Doctrinally, epistemologists had hoped to justify scientific knowledge on the basis of the data of the senses. The two projects are connected, in the sense that the clearer the terms, the likelier the truths in them will be revealed or derivable from obvious truths. So if the obvious concepts of mathematics, for instance were reducible to the clear concepts of logic, so also the truths of mathematics are reducible to the truths of logic. But this is not so. The truths of mathematics were reducible to set theory and not logic. The problem here is that the truths of set theory are less obvious and certain than mathematical truths. Since $20^{\mathrm{lh}}$ century mathematicians had discovered this truth and the mathematical doctrinal project got stalled (Quine1985; 17-19).

The same thing happened to epistemology according to Quine. Empiricist like Hume sought similar cooperation between the conceptual and doctrinal studies. Epistemologists like mathematicians enjoy and make progress on the conceptual project only to the extent that they resorted to the use of set theory by expanding their resources from simple impressions to sets of impressions and contextual definition. That is, defining concepts by translating whole sentences containing the concept. Like the mathematical project, the epistemological doctrinal project was stalled due to its failure to justify generalization and single future tense statements. Hume had identified bodies with sense impressions. Though he was able to maintain that some singular statements (statements about impressions immediately present) about bodies were indubitable yet neither general statement of existence nor proposition about the future gain any degree of certainty (certitude) even though he identified bodies with impression (Quine1986:2; Quine1985;16.17). For instance a generalization against observable trait such as "snow is white" will cover more cases than can actually be observed hence the futility of justifying of science in terms of immediate experience in a firmly logical way. Thus, as Quine notes." the humean predicament is the human predicament" (Quine.1985; 17). Thus. Quine argues that the aim of traditional epistemology of deducing science from indubitable truths of sense evidence must be denied.

Quine, in other to drive home his point that traditional epistemology is unproductive and conclude that it cannot produce knowledge, attacks two famous program of traditional epistemology. They are the Cartesian and carnapian programs (Quine 1985; 17-19). Quine breaks the Cartesian programme into two parts, the conceptual and the doctrinal parts. The Cartesian conceptual project seeks to define knowledge or justification, that is, seeks to find a set of rules which can be used to determine whether a given claim or belief is justified or not (knowledge is justified true belief on traditional epistemology's account) by deducing the belief in question from basic beliefs. The doctrinal side's main aim is to show that a given belief is justified because it meets the criterion or condition that it can be deduced from some self justify basic beliefs.

Due to lack of foundational justified beliefs and the strengths of justification required for inference, the Cartesian programme could not provide or find anything of substance (belief), which is justified. This truth is not contestable. Finally, Quine's total disappointment with traditional epistemology grows out of his contention that even Carnaps model foundational program is inadequate. The Canarpian project has both conceptual and doctrinal sides also.

The conceptual element seeks to find out which beliefs are justified by reducing them to idea of sensory terms while the doctrinal elemen seeks to use the: conceptual part to justify beliefs about truths of science which are reduced to sensory terms. Doctrinally, Carnap's work, according to Quine, did nothing to advance the" quest for certainty" (Quine I 985; 18) in the face of humean problems. On the conceptual side, translation is impossible. According to him, Carnap admitted this when he later propose "reduction form" which merely gave implications of the sentences in question rather than translation equivalences. Since Carnap has abandoned translation equivalences then his rational reconstruction has no advantage over psychology (Quine 1985; 18,19).

It should be noted that Carnap engages in the translation of statements, so Quine invokes Duhem's confirmation holism, which holds that only theories not individual statements are ever confirmed or disconfirmed. He also applied Peire's verificationism which holds that the equation of meaning with method of empirical confirmations to argue that only blocks of theory not individual statement have meaning (meaning holism). Quine then infers from meaning holism that if individual have no meaning of their own, then there are no facts of the matter to determine the correctness of translation of individual statements, so transition is impossible and hence the failure of Carnap's attempt at translation and thus all the creative attempts at reconstruction failed (Quine,1985;19). 


\section{QUINE AND THE ISSUE OF KNOWLEDGE PRODUCTIVITY}

In other to understand further Quine's disappointment and why he called for a replacement epistemology, we may need to ask; What epistemology would have gained if the Cartesian and Carnapian Programmes had succeeded. If they had succeeded we would have had the criterion of knowledge, that a belief is justified if it is indubitable(Marek;2015,63,64)

We will also have a type of formula that can be used to determine if any belief is justified or not, In short the task of first philosophy would have been achieved. The second question is, what does the failure of these programs amount to? It reveals that neither of the programs can lead to the idea of knowledge (justification) nor tell us what belief(s) is known or justified.

Since this type of foundational programs have dominated epistemology for nearly its entire life, it means traditional epistemology has not been able to provide criterion of knowledge and has not been able to show that a single belief is justified or known in the philosophical sense. That is, it has not produced any challenge free or viable theory of knowledge, hence, the issue or problem of knowledge productivity that Quine raised.

It should be noted that traditional epistemology had claimed that knowledge is possible; contrary to the skeptics claim that knowledge is impossible(Oke;1990,9,10). Though they accept the skeptic's premise that knowledge is certainty but reject the skeptics' conclusion that knowledge is impossible(Oke;1990,9,10). The onus of proof now lies with the traditional epistemologists to show that knowledge (since knowledge is certainty) can be attained. Hence the struggle of these epistemologists to show that certainty (knowledge) is achievable.

However. Quine tries to show that their efforts since inception or beginning of the struggle has not produced knowledge (certainty) with regard to empirical knowledge. So, Quine concludes that their effort have not yielded or produced knowledge and cannot produce a viable and unchallenging theory of knowledge. For him, traditional epistemology cannot produced knowledge because one, it has not produced one and so cannot; two, it is not the task of traditional epistemology to validate or justify our knowledge of the world (Quinel 985; 20).

It is pertinent at this juncture to note that traditional epistemology is concerned with the study of knowledge in general while naturalized epistemology is concerned with how we arrive at our beliefs - a causal study of our beliefs (Stroud;1985, 71-74). Traditional epistemology is also concerned with how we ought to arrive at our beliefs (Kornblilh 1985; 1-3).

There are two main tasks of tradition epistemology. One. it seeks to identify the regulating criterion for knowledge. Two, it tries to determine, based on this criterion; whether or not we have knowledge. If it had achieved its aim of providing a criterion for knowledge, one should be able to determine whether a given belief is justified or not now. The two epistemologies do not have the same concern and aims. So Quine's claim that traditional epistemologists aim is not to justify claims to know seems untenable. Traditional epistemologists seek to show how we can avoid errors in our knowledge - seek knowledge that is error free. That is, under what conditions one can claim to be justified in his claim to know (certainty).

According to Theodore. S (Jn.) and Lewis v.(2003,17,21) traditional epistemology's aim is the pursuance of truth and avoidance of error by setting criteria of knowing by which we ought to know(including assumed beliefs) not actually how we "know" or acquire our beliefs. It is concerned with how to justify our claims to know and whether our claims are true (as we ought to know) without error or eternally.

At this junction it is imperative to note that this aim of traditional epistemology has not been achieved. I quite agree to some extent with Quine that if epistemology is not to become a wild goose chase, it should be now possible to specify definitely what would be an acceptable solution to its normative (criteriological) problem. However, it is not over until it is over. The fact that an unchallenged or a challenged free theory of knowledge has not been produced by traditional epistemology does not mean that it cannot produce one.

So the leap from "it has not" to ";it cannot" by Quine is unjustifiable and untenable. The fact that medical science has not gotten a cure for AIDS (acquired immune deficiency syndrome) is not a criterion that solution will not be found to it one day. Thus, we must not abandon the search for solution to the problem of traditional epistemology. More so, that naturalized epistemology cannot provide solutions to the problem of traditional epistemology. For instance, naturalized epistemology cannot answer the question of knowledge in general or how we can have knowledge that is error -free or How ought we to know, how can we validate claims to know (Stroud,1985,74).

It may be argued that this search seems unproductive and time wasting and seems to be getting nowhere. It seems so, but it does not follow that solution will not be gotten one day. Just as we may not abandon the search for AIDS because a cure has not been gotten, so also we ought not to abandon the search for justification of knowledge. As a matter of fact the search has produced some theories of epistemic justification such as foundationalism, coherenism and contextualism though they are not yet satisfactory.

Traditional epistemology is on the way to producing a challenged free theory of epistemic justification though it is yet to arrive. Thus, it is not right to say it cannot produce one. It is not a philosophical virtue to run away from problems. Concerning philosophical questions such as traditional epistemology's questions, Russell 
admits "no answer can be found in the laboratory" yet "the studying of these questions, if not the answering of them is the business of philosophy". For this reason, Russell counsels that this search must not be abandoned (Russell 1976:90) The philosophical task is to provide attempted answers and alternative solutions. (Makinde; 2007, 23). So, Quine's call for the abandonment of traditional epistemology is unjustifiable.

\section{CONCLUSION}

This paper has examined Quine's claim that traditional epistemology should be abandoned on the basis that it is unproductive because it has not produced knowledge and therefore cannot produce one. The paper, after examining Quine's arguments for the call for the abandonment of traditional epistemology, reveals that the call is unjustifiable. This is because it is based on the reasoning that since traditional epistemology has not produced a viable theory it can never produce one. The fact that the much sought for cure for AIDS has not been achieved does not mean that a cure cannot be achieved someday. The paper also revealed that, contrary to Quine's claim, it is the aim of traditional epistemology to provide a foundation for science.

\section{REFERENCES}

Kornblith(ed.) (1985) Cambridge Massachusetts MIT press.

Kornblith naturalizing epistemology (1985) Cambridge MIT press

Makinde M. (2007): "The question of African philosophy" in African philosophy: The Demise of A controversy, lie Ife; Obafeini Awolowo university press limited.

Marek Jakubiee (2015) "Interpretation of Quine's naturalized epistemology and the character of naturalization of law". DOI:http//dx.doi.org/10.15633/ss.1079.(63,64).

Oke (1990), "A critical study of the viability of phenomenalism as an alternative theory of perception $\mathrm{PhD}$. Thesis of Obafemi Awolowo University. Ile ife.

Quine W. V. (1986): The philosophy of w.v: Quine an expository essay USA: Univ. press of Florida.

Quine (1985):"Epistemology naturalized" in Naturalized Epistemology Hillary kornblith (ed.) Cambridge Massachusetts MIT press.

Russell. B (1976): The problem of philosophy: with New Introduction by John S.,. London: oxford university press.

Stroud (1985): "the significance of naturalized epistemology" in Naturalizing epistemology Hillary kornblith (ed.) Cambridge Massachusetts MIT press.

Theodore S.(jnr) and Lewis V. (2003): Doing philosophy: An introduction through thought experiments, New York: McGraw Hill co. 